\title{
Intergenerational Bonding in Family and School Contexts: Which Does Impact More on Degree Aspiration of Students?
}

\author{
S. M. Shahidul ${ }^{1}$ \& A. H. M. Zehadul Karim ${ }^{2}$ \\ ${ }^{1}$ Department of Sociology \& Anthropology, Faculty of Islamic Revealed Knowledge \& Human Sciences, \\ International Islamic University of Malaysia, Jalan Gombak, Kuala lumpur, Selangor, Malaysia \\ Correspondence: A. H. M. Zehadul Karim, Department of Sociology \& Anthropology, Faculty of Islamic \\ Revealed Knowledge \& Human Sciences, International Islamic University of Malaysia, Jalan Gombak, 53100, \\ Kuala lumpur, Selangor, Malaysia. Tel: 60-36-196-6100. Fax: 603-6196-5041. E-mail: ahmzkarim@yahoo.com
}

Received: June 12, 2015 Accepted: July 13, 2015 Online Published: November 20, 2015

doi:10.5539/ass.v11n27p63 URL: http://dx.doi.org/10.5539/ass.v11n27p63

\begin{abstract}
Among the factors which have trajectory roles on the academic attainment of students, intergenerational bonding is the foremost of them. Though intergenerational bonding has basically focused on parent-child relationship, contemporary studies further consider the teacher-student relationship as intergenerational bonding to identify its effect on the academic attainment of students. In this study, we first examine both types of bonding which are created by parent-child and teacher-student relationships and how these impact on the degree of aspiration of secondary school students. Then, we compare these effects to identify which factor affects more on the degree aspiration outcome of students. We use the data collected from 553 students of Grade IX from 12 secondary schools in Bangladesh. The effect size of parent-child bonding and teacher-student bonding are compared using standardized Beta $(\beta)$ weights of these two variables. The results show that beyond the socioeconomic status, both parent-child bonding and teacher-student bonding significantly and positively impact on students' degree aspiration outcome. Furthermore, when we compared the effect size of these two variables, results show that parent-child bonding had more strength compared to teacher-student bonding to predict the degree aspiration outcome of students.
\end{abstract}

Keywords: academic outcome, educational aspiration, intergenerational bonding, relationship, family, cultural influence

\section{Introduction}

To identify the academic outcomes of students, intergenerational bonding typically has been studied in terms of parent-child relationship. We further argue that other types of intergenerational bonding are also affecting the academic achievement of students. For instance, in schools, adolescents regularly interact with their teachers who can serve as mentors, models of good behavior and sources of support for the students (Pianta, Steinberg, \& Rollins, 1995). Our study focuses on intergenerational bonding, examining students' general feelings about their teachers which is based on the past research of Sanders and Jordan (2000) and Steinberg, Brown \& Dornbusch (1996). Relationship is the initial source of bonding in which many factors underlie to sustain the links between the agents. Relationships have been extensively studied in many contexts such as schools and families to identify the educational benefits of students. In this respect, a number of literature demonstrates how the alienation of students contributes to their academic problems and conversely, how integration of students contributes to academic improvement. Interdisciplinary literature on adolescents' academic achievement suggests that students' affective tie with teachers promotes a favorable environment of learning and this communal learning environment transmits social capital from teachers to students (Birch \& Ladd, 1998; Pianta et al., 1995). From the basis of this theory, we can expect that positive relationship between teachers and students serves as a protective force for students, which encourages them to continue schooling instead of being early dropouts from school. On the other hand, the lower risk of early school dropout increases the level of educational aspiration of students.

Coleman and Hofer (1987) observe that the structural elements of schools, sector (public and private) and class size, are relevant to form the interpersonal relationships between teachers and students. They found that the intimacy between teachers and students occur more in private schools compared to public schools causing an 
improvement in the academic achievement of the students in the private schools. The attachment theory by Bowlby (1969) explains that students with positive relationships with their teachers consider their schools as more secure and they feel safer in schools. Meanwhile the Self-System theory emphasizes the importance of positive relationships between teachers and students (Harter, 2012; McCombs, 1986). Scholars argue that adolescents go to school to improve three basic psychological needs which are competence, autonomy and relatedness. Competence denotes the students' need to feel capable of their academic work. Autonomy refers to the ability to make decisions and relatedness implies the motivation of social connectedness to the teachers. Positive relationships with teachers can meet these needs for students.

Conventional sociological and psychological models demonstrate that a positive parent-child relationship promotes academic outcomes of students as do teacher-student bonding (Englund, Egeland, \& Collins, 2008; Spera, 2005). Although both parent-child and teacher-student relationships, enhance students' academic outcome, the literature is not much evident on how these two bondings directly impact students' degree aspiration which aims to examine this study. Our other objective is to identify, between parent-child bonding, and teacher-student bonding which has more effect on students' degree aspiration outcome.

\subsection{Teacher-Student Relationship and Academic Outcomes}

Among agents which have trajectory roles in the academic attainment of students, teachers are the foremost at all levels of schooling. In this respect, the attachment theory (Ainsworth, 1982; Bowlby, 1969) posits that students feel safe and secure in schools when they have a positive relationship with their teachers which in turn enhances their academic skills because, when a positive relationship is formed between them, classrooms generally become a supportive space which improves students' academic engagement. In this secure environment, students learn about the appropriate behaviors which enable them to face academic challenges. Murray and Malmgren (2005) found that students from low-income schools benefit more from positive student-teacher relationships compared to students from high-income schools. Some studies have found that students positive relationship with teachers is important when students transit from elementary to middle schools and middle to high schools which is called schooling attainment (Alexander et al., 1997). In respect to Math skills, Midgley et al. (1989) found that students who have less positive relationship with their teachers have less skills in Maths and students who tend to work on being close to their teachers significantly increase their Math skills. Murray and Malmgren (2005) discovered that students with low family background but have high involvement with teachers, have a high GPA, compared to whose who have low involvement with teachers when positive relationship improves the motivation of students which in turn improves their academic outcomes. In fact, the reason for the positive relationship between teacher-student relationships and academic achievement is motivation. In this respect, motivational theorists suggest that students' perceptions regarding their relationship with their teachers motivate them for good performance (Ryan, Stiller, \& Lynch, 1994; Wentzel, 2003). Students who perceive their relationship with teachers as positive are motivated to improve their academic achievement when positive relationship indicates supportive and caring environment for students. Muller, Katz and Dance (1999) argue that students' motivation is closely linked to teachers' expectations and further more, students shape their educational aspirations from the perception of their teachers' expectation. They also argue that students who have the perception that their teachers have higher expectations regarding their academic performance are motivated to meet their teachers' expectations. Wentzel (2003) observed that students in high-poverty typically have low academic self-esteem and self-efficacy. However, students who have high closeness with teachers, have high self-esteem and self-efficacy regardless of their family background status. Factors which effect on less bonding between teachers and students are highlighted next.

The research examines that male students typically have more conflict and are less close to their teachers compared to female students (Baker, 2006; Howes et al., 2000; Hughes, Cavell, \& Wilson, 2001).

- Students with more externalizing problems such as aggression and anxiety show more conflict with teachers compared to their counterparts (Murray \& Murray, 2004; O'Connor et al., 2012).

- Students who have problematic behavior at home or have conflict with family members also have less closeness with their teachers in schools (Birch \& Ladd, 1998; Murray \& Murray, 2004; O'Connor et al., 2012).

- Students who are less intelligent have a more negative relationship with their teachers compared to those who are more intelligent (Murray \& Greenberg, 2001).

- $\quad$ Students who have no preschool experience feel shy to be close to their teachers (Rudasill et al., 2006). 


\subsection{Parent-Child Relationship and Academic Outcomes}

Sociologists have underscored on the positive relationship between parents and children, especially in developing the academic attainment of students when a close relationship between parents and children indicates that parents are more likely to involve in their children's education. Brooks-Gunn \& Markman (2005) demonstrate that communication between parents and children is positively associated with children's intellectual level and academic achievement. They also found a positive association between children's educational aspiration and their relationship with parents. Some researchers have found that there is a strong positive association between positive relationship between parents and children and school completion among youth who are at risk to drop out. Spera (2005) examined the data on the closeness and cohesion between parents and children, and observes that closeness strongly affects children's psychological development and their academic achievement. He also discovers that strong parent-child relationship is positively correlated to students' college enrollment because, students with a close relationship with their parents achieve higher grades and test scores. Dornbusch et al. (1987) argue that positive relationships between parents and children provide mental support and supportive family environment for children which further enhance educational outcomes for them. In fact, studies that investigate the link between parent-child relationship and academic attainment of children have found that strong relationships accelerate student enrollment from primary to secondary schools and from secondary to post secondary education.

\subsection{Cultural Influence in Parent-Child Relationship}

Relational dynamics are typically embedded within a cultural context. According to the Basic Relationship Theory (Hinde, 1997), various levels of human complexities such as interaction, relationship, individual, group, and socio-cultural structure have reciprocal influences on each other. Valsiner (2000) argues that culture orients humans in their social environment. The importance of culture in the context of the parent-child relationship is the concept of generation. Historical analysis (Alwin, 1996) demonstrates that cultural values change from one generation to another due to several socioeconomic evaluations and technological changes in which parents and child demonstrate different values in their respective childhood. Parents' influence children's values during childhood period, but this influence becomes less important in adulthood as children get contract with many in this period. Parents tend to transfer their values and practices that they gain from their generation in their parenting and consequently, intergenerational transmission for children comes with the values and practices of former generations. However, parents also tend to teach their children contemporary values and practices in developing their reciprocal relationships. In this respect, Kuc-zynski et al. (1997) develop a model to show how parental values, beliefs and practices transmit into children in their relational environment and culture.

\section{Methods}

\subsection{Participants}

This study is based on a survey carried out in one of the town zones of Pirgonj Upazila of Rangpur District in Bangladesh in February, 2014 using interviews with questionnaires. We randomly selected 12 secondary schools. We contacted students of Grade IX and received responses from 553 students.

\subsection{Measurement of the Variables}

\subsubsection{Degree Aspiration}

The dependent variable of this study is the degree aspiration of the secondary high school students, which was measured by the question, "What is the highest academic degree you would like to obtain in your lifetime (circle only one below)? 1 = less than high school graduation, 2 = high school education only, $3=$ less than two years of college, vocational or business school, $4=$ two or more years of college including two-year degree, $5=$ Bachelor's degree, $6=$ Master's degree or equivalent and $7=\mathrm{PhD}, \mathrm{MD}$ or other professional degree.

\subsubsection{Parent-bonding}

We measured parent-child bonding following the questionnaire by Ruth et al. (2010) on closeness dimension consisting of five items: (a) How close do you feel for your mother/father?, (b) How much do you think she/he cares about you?, (c) How much do you agree/disagree that your mother/father is warm and loving toward you?, (d) How much do you agree/disagree that when you do something wrong that is important, your mother/father talks about it with you and helps you understand why it is wrong?, (e) How much do you agree/disagree that you are satisfied with the way your mother/father and you communicate with each other? All items were coded on a scale from 0 to 4 in which higher scores indicating greater closeness. We created an index of parental-bonding by adding the scores of all five items for each participant, which ranged from 5 to 20 . The parent-bonding scale was found to have acceptable internal consistency with an alpha of .86 . 


\subsubsection{Teacher-bonding}

We measured teacher-student bonding following the technique by Crosnoe et al. (2004) in which students were asked three items about their teachers: (a) How much do you get in trouble with teachers?, (b) Do you feel that teachers care about you?, and (c) How do you believe that teachers treat students fairly in school? Responses ranged from 1 to 5 (almost every day to never for the first item, never to very much for the second item and strongly disagree to strongly agree for the third item). We created an index of teacher-bonding by adding the scores of all three items for each participant, which ranged from 3 to 15 . The teacher-bonding scale was found to have acceptable internal consistency with an alpha of .81 .

\subsubsection{Control Variables}

We controlled the three foremost affecting variables on students' educational aspiration which are: (a) sample parental education, and (b) students' academic achievements which were assessed from their average grades of the last exam and (c) number of dropout peers.

\subsection{Analytic Strategy}

A series of multiple linear regression analyses were performed to measure the influence of parent-child bonding and teacher-student bonding on the dependent variable of degree aspiration. We measured the standardized coefficients of our studied variables. Therefore, to compare the effect size of parent-child bonding and teacher-student bonding, we considered the Beta ( $\beta$ ) weight of these two variables. In this case, Beta which has more value was considered as the more effective variable on educational aspiration in general.

\section{Results}

Table 1. Multiple linear regression analyses

\begin{tabular}{|c|c|c|c|c|c|c|}
\hline Variables & \multicolumn{2}{|c|}{ Model 1} & \multicolumn{2}{|c|}{ Model 2} & \multicolumn{2}{|c|}{ Model3 } \\
\hline Dependent variable $=$ Degree aspiration & \multicolumn{2}{|c|}{$\beta(\mathrm{SE})$} & \multirow{2}{*}{\multicolumn{2}{|c|}{$\begin{array}{c}\beta(\mathrm{SE}) \\
9.28^{* * *}(2.68)\end{array}$}} & \multicolumn{2}{|c|}{$\beta(\mathrm{SE})$} \\
\hline Constant & $11.56 * * *$ & $(3.31)$ & & & $6.37 * * *$ & $(2.11)$ \\
\hline Academic achievement & $.77 * * *$ & $(.31)$ & $.62 * * *$ & $(.29)$ & $.46^{* * *}$ & $(.18)$ \\
\hline Parental education & $.62 * * *$ & $(.22)$ & $.55^{* *}$ & $(.20)$ & $.33^{* *}$ & $(.17)$ \\
\hline Number of dropout peers & $-.73 * *$ & $(.32)$ & $-.61 * *$ & $(.18)$ & $-.31^{*}$ & $(.11)$ \\
\hline Parental-bonding & & & $.84 * * *$ & $(.25)$ & $.76^{* * *}$ & $(.21)$ \\
\hline Teacher-bonding & & & & & $.53 * * *$ & $(.20)$ \\
\hline$R^{2}$ & \multicolumn{2}{|c|}{.26} & \multicolumn{2}{|c|}{.38} & \multicolumn{2}{|c|}{.44} \\
\hline
\end{tabular}

$\mathrm{P}^{*}<.05, \mathrm{P}^{* *}<.01, \mathrm{P}^{* * *}<.001$

Results in Model 3 demonstrate that academic achievement has a critical beneficial outcome on the degree aspiration of students $(\beta=.46, \mathrm{P}<.001)$. It implies, if academic achievement becomes higher, the level of degree aspirations also significantly becomes higher. Correspondingly, the coefficient of parental education $(\beta=.33, \mathrm{P}$ $<.001)$ implies that if parental level of education increases, students' level of degree aspiration significantly increases. The number of having dropout friends shows the converse result $(\beta=-.31, P<.05)$ which indicates that if students have more friends who have school dropout status, then their aspiration level decreases. However, after controlling these variables we can observe that parental-bonding with children significantly and positively impacts on students' degree aspiration $(\beta=.76, \mathrm{P}<.001)$. This result indicates that if parental-bonding with children becomes greater, the level of degree aspiration of students also becomes higher. Similarly, teacher-bonding with students also has a significant positive impact on students' degree aspiration $(\beta=.53, \mathrm{P}$ $<.001)$. This result implies that if teacher-bonding with students is increased, students' level of degree aspiration increases. Furthermore, we observe that the standardized coefficient of parent-bonding is bigger than the standardized coefficient of teacher-bonding. Therefore, though both parent-bonding and teacher-bonding significantly and positively impact on degree aspiration, parent-bonding has a more straight effect on degree aspiration of students compared to the effect of teacher-bonding.

\section{Discussion}

Results of this study show that parent-child bonding has more impact on students degree aspiration compared to 
teacher-student bonding. There are many causes for this massive influence of parent-bonding with children in educational attainment. Parent-bonding may help to improve the cognitive development of children (Pedersen, Anderson \& Kain, 1980) which enhances their educational expectations. Children who have close relationships with parents, typically have parents who have higher involvement in their children's education. Children with more parental care are more likely able to handle the unfamiliar situations and be more curious to learn the facts (Pruett, 1997). In fact, children who have close bonds with parents, have strong ability to overcome toggle troubled and stressful situations. Children with close bonding with parents typically become more competent, curious and willing to explore the surroundings with consequently better performance in their academic life. In respect to the benefit of close-relationships between parents and children, scholars have found that children with more close relationship experience less depression in their academic life (Dubowitz et al., 2001), have a less negative attitude toward negative emotionality and psychological distress (Easterbrooks \& Goldberg, 1990), have higher level of self satisfaction and fewer level of anxiety (Flouri, 2005). Children with close relationships with parents also have superior problem solving power, adaptive skills and appropriate manner in self-efficacy, internalizing and externalizing behaviors, and less acting out in school (King, 2006). Children who feel close to their parents tend to show less antisocial behavior, hyperactivity and bullying behavior. To identify the benefits of a close relationship between parents and children, Horn and Sylvester (2002) and Kelly (2000) demonstrate that children who live without their fathers, are more likely to have problems performing in school such as getting lower scores on academic performance, poor intellectual ability and even peer week study. These children are more likely to have higher behavioral problems at schools such as less attention in class, disobedience, poor school attendance, being expelled and less likely to graduate high schools which consequently cause them less likely to enroll in college. They are more likely to choose deviant peers which may have a negative impact on their academic attainment and engaging them in deviant behavior and school crime. The authors also have found that parental closeness with children has a negative correlation with children getting drugs through friends. Ellis et al. (2003) have found that female adolescents who live without parents are more likely to experience early pregnancy before completing their school and consequently, they are more likely to become early dropouts from schools. DeLuccie (1996) and Russell (1982) found that children who have close relations with parents have more self-confidence and feel more encouraged to be involved in their academic activities. In fact, the family is the primary agent of value socialization and construction for children, which enhances the adaptive power of children to perform in complex circumstances. Positive parent-child relationships, create positive academic motivation for children. Children typically tend to be motivated from the beginning and a positive bonding with parents can also improve children's school related learning and challenges. Attachment theory demonstrates that children develop motivational or behavioral control systems that foster the shape and maintenance of a parent-child attachment bond (Cassidy, 1999).

\section{Conclusion}

Although parent-child bonding has a greater effect on students' degree aspiration outcome compared to teacher-student bonding, the quality of parent-child bonding sometimes depends on the quality of the parents. In this regard, highly qualified parents are likely to have quality relationships with their children. In other words, parents who have higher education and or with higher occupational status typically tend to build close relationship with their teachers as educated parents can better understand the psycho-emotional complexities of their children. Teacher-student bonding also has a significant impact on students' degree aspiration outcome. Hence, students with risk to develop positive teacher-student relationships, meet challenges to better perform in schools which discourages them from not continuing schooling. Hence, teachers need to make special efforts to support problematic students. However, teachers may vary in their ability to develop close relationships with students and in this case, some socio-emotional factors of teachers such as individual personality and feelings toward students, play an important role. Finally, to better understand the underlying factors of parents-bonding and teachers-bonding, it requires which particular factors influence to create closer relationships between them and which can be sourced for the future research. Furthermore, this study has been conducted by using a small sampling area. The techniques of this study can be directions for future studies to explore the aspiration issue by using wider sampling regions.

\section{Acknowledgements}

The authors are grateful to the "Research Management Centre (RMC) and the department of Sociology \& Anthropology", IRKHS, International Islamic University of Malaysia for the academic support, including financial resources which allowed them to write this paper. 


\section{References}

Ainsworth, M. D. S. (1982). Attachment: Retrospect and prospect. In C. M. Parkes, \& J. Stevenson-Hinde (Eds.), The place of attachment in human behavior (pp. 3-30). New York: Basic Books.

Alexander, K. L., Entwisle, D. S., \& Horsey, C. S. (1997). From first grade forward: Early foundations of high school dropout. Sociology of Education, 2(70), 87-107. http://dx.doi.org/10.2307/2673158

Alwin, D. F. (1996). Parental socialization in historical perspective. In C. D. Ryff, \& M. M. Seltzer (Eds.), The parental experience in midlife (pp. 105-167). Chicago, IL: University of Chicago Press.

Baker, J. A. (2006). Contributions of teacher-student relationships to positive school adjustment during elementary school. Journal of School Psychology, 3(44), 211-229. http://dx.doi.org/10.1016/j.jsp.2006. 02.002

Birch, S. H., \& Ladd, G. W. (1998). Children's interpersonal behaviors and the teacher-child relationship. DevelopmentalPsychology, 34(5), 934-946. http://dx.doi.org/10.1037/0012-1649.34.5.934

Bowlby, J. (1969). Attachment and loss (Vol. 1: Attachment). New York: Basic Books.

Brooks-Gunn, J., \& Markman, L. B. (2005). The Contribution of Parenting to Ethnic and Racial Gaps in School Readiness. Future of Children, 15(1), 139-165.

Bruner, J. (1996). The culture of education. Cambridge, MA: Harvard University Press. http://dx.doi.org/10.1353/foc.2005.0001

Cicchetti, D., \& Cummings, E. M. (Eds.). (n. d.). Attachment in the preschool years: Theory, research and intervention (pp. 221-244). Chicago: University of Chicago Press.

Coleman, J. S., \& Hoffer, T. B. (1987). Public and Private Schools: The Impact of Communities. New York: Basic.

Crosnoe, R., Johnson, M. K., \& Elder, G. H. Jr. (2004). Intergenerational bonding in school: The behavioral and contextual correlates of student-teacher relationships. Sociology of Education, 77(1), 60-81. http://dx.doi.org/10.1177/003804070407700103

DeLuccie, M. F. (1996). Predictors of paternal involvement and satisfaction Psychological Reports, 79, 1351-1359. http://dx.doi.org/10.2466/pr0.1996.79.3f.1351

Dornbusch, S. M., Ritter, P. L., Leiderman, P. H., Roberts, D. F., and Fraleigh, M. J. (1987). The relation of parenting style to adolescent school performance. Child Dev., 58, 1244-1257. http://dx.doi.org/10.2307/ 1130618

Dubowitz, H., Black, M. M., Cox, C. E., Kerr, M. A., Litrownik, A. J., Radhakrishna, A., ... Runyan, D. K. (2001). Father involvement and children's functioning at age 6 years: A multisite study. Child Maltreatment: Journal of the American Professional Society on the Abuse of Children, 6(4), 300-309. http://dx.doi.org/10.1177/1077559501006004

Easterbrooks, M. A., \& Goldberg, W. A. (1990). Security of toddler-parent attachment: Relation to children's sociopersonality functioning during kindergarten.

Ellis, B. J., Bates, J. E., Dodge, K. A., Fergusson, D. M., Horwood, J., Pettit, G. S., \& Woodward, L. (2003). Does father absence place daughters at special risk for early sexual activity and teenage pregnancy? Child Development, 74(3), 801-821.

Englund, M., Egeland, B., \& Collins, W. A. (2008). Exceptions to high school dropout predictions in a lowincome sample: Do adults make a difference? Journal of Social Issues, 64(1), 77-93. http://dx.doi.org/10.1111/j.1540-4560.2008.00549.x

Flouri, E. (2005). Fathering and child outcomes. West Sussex, England: John Wiley \& Sons Ltd. http://dx.doi.org/10.1002/9780470713228

Harter, S. (2012). The construction of the self. Developmental and sociocultural foundations. New York: Guilford Press.

Hinde, R. A. (1997). Relationships: A dialectical perspective. United Kingdom: Taylor \& Francis Publishers.

Horn, W. F., \& Sylvester, T. (2002). Father Facts (4th ed.). National Fatherhood Initiative. Retrieved from http://www.fatherhood.org/fatherfacts.htm

Howes, C., Phillipsen, L. C., \& Peisner-Feinberg, E. (2000). The consistency of perceived teacher-child 
relationships between preschool and kindergarten. Journal of School Psychology, 58(2), 115-132. http://dx.doi.org/10.1016/s0022-4405(99)00044-8

Hughes, J. N., Cavell, T. A., \& Wilson, V. (2001). Further support for the developmental significance of the quality of the teacher-student relationship. Journal of School Psychology, 39(4), 289-301. http://dx.doi.org/10.1016/S0022-4405(01)00074-7

Kelly, J. B. (2000). Children's adjustment in conflicted marriage and divorce: A decade review of research. Journal of the American Academy of child and Adolescent Psychiatry, 39(8), 963-973. http://dx.doi.org/10.1097/00004583-200008000-00007

King, V. (2006). The antecedents and consequences of adolescents' relationships with stepfathers and nonresident fathers. Journal of Marriage and Family, 68(4), 910-928. http://dx.doi.org/10.1111/j.1741-3737.2006.00304.x

Kuczynski, L., \& Hildebrandt, N. (1997). Models of conformity and resistance in socialization theory. In J. E. Grusec, \& L. Kuczynski (Eds.), Parenting and the internalization of values: a handbook of contemporary theory (pp. 227-256). NewYork: Wiley.

McCombs, B. L. (1986). The role of the self-system in self-regulated learning. Contemporary Educational Psychology, 11, 314-332. http://dx.doi.org/10.1016/0361-476X(86)90028-7

Midgley, C., Feldlaufer, H., \& Eccles, J. S. (1989). Student/teacher relations and attitudes toward mathematics before and after the transition to junior high school. Child Development, 60(4), 981-992. http://dx.doi.org/10.2307/1131038

Muller, C., Katz, S. R., \& Dance, L. J. (1999). Investing in teaching and learning dynamics of the teacher-student relationship from each actor's perspective. Urban Education, 34(3), 292-337. http://dx.doi.org/10.1177/ 0042085999343003

Murray, C., \& Greenberg, M. T. (2001). Relationships with teachers and bonds with school: Social and emotional adjustment correlates for children with and without disabilities. Psychology in the Schools, 38(1), 25-41. http://dx.doi.org/10.1002/1520-6807(200101)

Murray, C., \& Malmgren, K. (2005). Implementing a teacher-student relationship program in a high- poverty urban school: Effects on social, emotional, and academic adjustment and lessons learned. Journal of School Psychology, 43(2), 137-152. http://dx.doi.org/10.1016/j.jsp.2005.01.003

Murray, C., \& Murray, K. M. (2004). Child level correlates of teacher-student relationships: An examination of demographic characteristics, academic orientations, and behavioral orientations. Psychology in the Schools, 41(7), 751-762. http://dx.doi.org/10.1002/pits.20015

O'Connor, E. E., Collins, B. A., \& Supplee, L. (2012). Behavior problems in late childhood: The roles of early maternal attachment and teacher-child relationship trajectories. Attachment \& Human Development, 14(3), 265-288. http://dx.doi.org/10.1080/14616734.2012.672280

Pianta, R. C., Steinberg, M. S., \& Rollins, K. B. (1995). The first two years of school: Teacher-child relationships and deflections in children's classroom adjustment. Development and Psychopathology, 7(2), 295-312. http://dx.doi.org/10.1017/S0954579400006519

Pruett, K. D. (1997). How men and children affect each other's development. Zero to Three, 18(1), 3-11.

Rudasill, K. M., Rimm-Kaufman, S. E., Justice, L. M., \& Pence, K. (2006). Temperament and language skills as predictors of teacher-child relationship quality in preschool. Early Education and Development, 17(2), 271-291. http://dx.doi.org/10.1086/209546

Ruth, J. A., Otnes, C. C., \& Brunel, F. F. (1999). Gift Receipt and the Reformulation of Interpersonal Relationships. Journal of Consumer Research, 25(4), 385-402.

Ryan, R. M., Stiller, J. D., \& Lynch, J. H. (1994). Representations of relationships to teachers, parents, and friends as predictors of academic motivation and self-esteem. The Journal of Early Adolescence, 14(2), 226-249. http://dx.doi.org/10.1177/027243169401400207

Sanders, M. G., \& Jordan, W. J. (2000). Student-teacher relations and academic achievement in high school. In M. G. Sanders (Ed.), School Students Place At Risk (pp. 65-82). Mahwah, New Jersey: Lawrence Erlbaum Associates.

Spera, C. (2005). A review of the relationship among parenting practices, parenting styles, and adolescent school 
achievement. Educational Psychology Review, 17, 125-146. http://dx.doi.org/10.1007/s10648- 005-3950-1

Valsiner, J. (2000). Culture and Human Development. Thousand Oaks, CA: Sage.

Wentzel, K. R. (2003). Sociometric status and adjustment in middle school: A longitudinal study. The Journal of Early Adolescence, 23(1), 5-28. http://dx.doi.org/10.1177/0272431602239128

\section{Copyrights}

Copyright for this article is retained by the author (s), with first publication rights granted to the journal.

This is an open-access article distributed under the terms and conditions of the Creative Commons Attribution license (http://creativecommons.org/licenses/by/3.0/). 